\title{
Biomarkers for Stroke
}

\author{
Suk Jae Kim, ${ }^{\mathrm{a}}$ Gyeong Joon Moon, ${ }^{\mathrm{b}}$ Oh Young Bang ${ }^{\mathrm{a}}$ \\ ${ }^{a}$ Department of Neurology, Samsung Medical Center, Sungkyunkwan University School of Medicine, Seoul; \\ ${ }^{b}$ Clinical Research Center, Samsung Biomedical Research Institute, Seoul, Korea
}

Background Major stroke clinical trials have failed during the past decades. The failures suggest the presence of heterogeneity among stroke patients. Biomarkers refer to indicators found in the blood, other body fluids or tissues that predicts physiologic or disease states, increased disease risk, or pharmacologic responses to a therapeutic intervention. Stroke biomarkers could be used as a guiding tool for more effective personalized therapy.

Main Contents Three aspects of stroke biomarkers are explored in detail. First, the possible role of biomarkers in patients with stroke is discussed. Second, the limitations of conventional biomarkers (especially protein biomarkers) in the area of stroke research are presented with the reasons. Lastly, various types of biomarkers including traditional and novel genetic, microvesicle, and metabolomics-associated biomarkers are introduced with their advantages and disadvantages. We especially focus on the importance of comprehensive approaches using a variety of stroke biomarkers.

Conclusion Although biomarkers are not recommended in practice guidelines for use in the diagnosis or treatment of stroke, many efforts have been made to overcome the limitations of biomarkers. The studies reviewed herein suggest that comprehensive analysis of different types of stroke biomarkers will improve the understanding of individual pathophysiologies and further promote the development of screening tools for of high-risk patients, and predicting models of stroke outcome and rational stroke therapy tailored to the characteristics of each case.

Keywords Stroke, Ischemic; Biomarker; Personalized medicine; Risk factor; Treatment

\author{
Correspondence: \\ Oh Young Bang \\ Department of Neurology, Samsung \\ Medical Center, Sungkyunkwan \\ University, 81 Irwon-ro, Gangnam-gu, \\ Seoul 135-710, Korea \\ Tel: +82-2-3410-3599 \\ Fax: +82-2-3410-0052 \\ E-mail:nmboy@unitel.co.kr \\ Gyeong Joon Moon \\ Clinical Research Center, Samsung \\ Biomedical Research Institute, 81 Irwon-ro, \\ Gangnam-gu, Seoul 135-710, Korea \\ Tel: +82-2-2148-7328 \\ Fax: +82-2-2147-7385 \\ E-mail:neobios7@gmail.com
}

Received: September 2, 2012

Revised: December 26, 2012

Accepted: December 27, 2012

This study was supported by the Korean Healthcare Technology REtD Project, Ministry of Health \& Welfare (A110208) and the Bio \&t Medical Technology Developmental Program of the National Research Foundation of Korea, Ministry of Education, Science and Technology (2011-0019389).

The authors have no financial conflicts of interest.

\section{Discovering biomarkers for stroke}

In a narrow sense, biomarkers refer to indicators measured by chemical or biologic tests using blood or urine that predicts physiologic or disease states, or increased disease risk. Biomarkers are also a valuable tool in drug development, providing more accurate and complete information regarding drug performance, disease progression, or response to a specific drug therapy. In the research field of myocardial infarction, the role of biomarkers has been emphasized over a long period of time. Treatment according to the biomarkers has also been investigated in vari- ous diseases including diabetes or immunological disorders. On the contrary, there has been a relative dearth of biomarker research in cerebrovascular disease. Herein, we review the role of current and new stroke biomarkers with their strengths and weaknesses, focusing on the importance of comprehensive approaches.

\section{Learning from the failure of recent clinical trials}

Over the recent 10 years, numerous large multicenter ran- 
domized clinical trials (RCTs) on stroke patients have been performed in the stroke research field. However, almost all major studies including RCTs regarding secondary prevention of stroke, ${ }^{1-3}$ MR-based thrombolytic therapy, ${ }^{4,5}$ and STAIR (Stroke Treatment Academic Industry Roundtable) criteria-guided neuroprotection ${ }^{6}$ have failed to show meaningful clinical benefits. In this regard, several issues have been suggested to explain and overcome these failures.

First, it is warranted for more larger and methodologically sound RCTs which meet the STAIR ${ }^{7}$ and CONSORT ${ }^{8}$ (CONsolidated Standards Of Reporting Trials) criteria. These may enhance the success rate and reliability of the study. It is clear that findings derived from large-scale intervention trials have provided the impetus to change guidelines for stroke treatment. Nonetheless, direct application of RCTs results to daily clinical practice is dubious, because patients enrolled in large RCTs may not be representative of patients in our clinical practice. ${ }^{9}$

Second, there has been increasing interest in new statistical approaches to end-point analysis in RCTs (from dichotomized outcome scales to global statistics, responder, or shift analysis). ${ }^{10}$ These are mainly used to reduce sample size or enhance trial ef- ficiency. ${ }^{11}$ Unfortunately, however, researchers cannot draw any new findings from RCTs through the novel statistical methods.

Third, the importance of considering heterogeneity among stroke patients has emerged. Unlike coronary heart disease, stroke has heterogeneous pathophysiologies and mechanisms. Moreover, individual patients with stroke have different features even among subjects with same stroke mechanisms. These aspects enhance the need for development of personalized medicine based on the characteristics of each patient rather than performing large RCTs. Stroke biomarkers may provide the information on the heterogeneity and could be a guiding tool for more effective personalized therapy among patients with ischemic cerebrovascular disease.

\section{Role of biomarkers in stroke research}

Emerging roles of stroke biomarkers are summarized in Table 1. Although the roles of biomarkers are basically diagnosing the disease and predicting the outcome, biomarkers in patients with stroke can also provide a large variety of other information about the risk of future stroke, possible stroke mechanisms for bio-

Table 1. Emerging roles of stroke biomarkers

\begin{tabular}{|c|c|}
\hline Roles & Examples of biomarkers \\
\hline Screening high-risk (asymptomatic) subjects & $\begin{array}{l}\text { CRP, fibrinogen, and inflammatory cytokines for stroke risk }{ }^{15-18,20} \\
\text { WWF, BNP, and UACR* for stroke risk }{ }^{21,22} \\
\text { ADMA }^{\dagger} \text { for silent brain infarcts on } \mathrm{MRI}^{19} \\
\text { Genome-wide association studies of stroke }\end{array}$ \\
\hline $\begin{array}{l}\text { Rapid stroke diagnosis } \\
\text { for pre-hospital screening } \\
\text { Improve fast-tracking in emergency room } \\
\text { Ancillary data when contemplating thrombolysis }\end{array}$ & 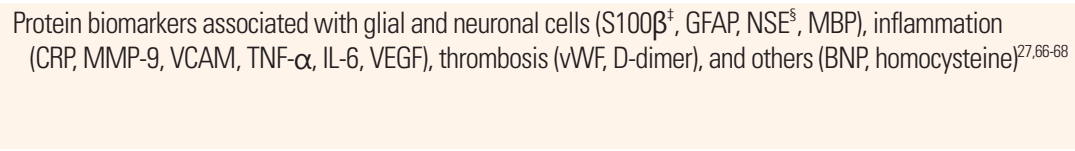 \\
\hline $\begin{array}{l}\text { Detection of possible stroke mechanisms } \\
\rightarrow \text { Biomarker-guided (molecular targeted) treatment }\end{array}$ & $\begin{array}{l}\text { Mechanisms of neuronal death, e.g. Glutamate, GABA } 30,31 \\
\text { Etiologic diagnosis of ischemic stroke } \text { s, } 28,69^{3}\end{array}$ \\
\hline Predicting drug response & $\begin{array}{l}\text { Pharmacogenomic studies for the resistance to aspirin, clopidogrel, warfarin, statin, or thrombolysis } \\
\alpha_{2} \text {-antiplasmin for recanalization after thrombolysis }{ }^{38} \\
\text { MMP9 and S100 } \beta \text { for a high risk of hemorrhagic transformation after thrombolysis }{ }^{35-37}\end{array}$ \\
\hline Predicting outcome & $\begin{array}{l}\text { Inflammatory markers for early neurological worsening } \\
\text { S100ß for delayed infarct expansion }{ }^{70,71} \\
\text { D-dimer for early recurrent ischemic lesion on DW/44 } \\
\text { Higher level of serum fibrin-monomer for thrombus formation in the left atrial appendage }{ }^{43} \\
\text { Lower D-dimer level for spontaneous early improvement in atrial fibrillation-related stroke }{ }^{41} \\
\text { wWF for adverse events (mortality and major bleeding) in anticoagulated atrial fibrillation patients }{ }^{42} \\
\text { WWF for further stroke or vascular events in atrial fibrillation patients who received aspirin }{ }^{72} \\
\text { BNP for functional outcome after atrial fibrillation stroke } \\
\text { Inflammatory markers (CPR, IL-6, etc.) for poor outcome after stroke } \\
\text { BDNF polymorphism predicts outcome after traumatic brain injury or SAH, and response to rTMS }{ }^{45,46}\end{array}$ \\
\hline Use as surrogate endpoints in clinical trials & $\begin{array}{l}\text { Troponin T, CRP, BNP/NT-proBNP } \\
\text { S100ß, nitric oxide for phase III trials }\end{array}$ \\
\hline
\end{tabular}

*Urinary albumin/creatinine ratio, a marker of endothelial dysfunction; ${ }^{\dagger}$ Asymmetrical dimethylarginine, an inhibitor of eNOS, a marker of endothelial dysfunction; ${ }^{\text {tProtein }}$ $S 100 \beta$, homologue for CK-MB in coronary heart disease; ${ }^{\S}$ Neuronal specific enolase, homologue for troponin in coronary heart disease.

CRP, C-reactive protein; VWF, von Willebrand factor; BNP, B-type natriuretic peptide; GFAP, Glial fibrillary acidic protein; MBP, Myelin basic protein; MMP, Matrix metalloproteinase; VCAM, Vascular cell adhesion molecule; TNF, Tumor necrosis factor; IL, Interleukin; VEGF, Vascular endothelial growth factor; GABA, Gamma aminobutyric acid; DWI, Diffusion-weighted imaging; BDNF, Brain-derived neurotrophic factor; SAH, Subarachnoid hemorrhage; rTMS, Repetitive transcranial magnetic stimulation; NT-proBNP, N-terminal probrain natriuretic peptide. 
marker-guided treatment, or drug response. In addition, they can be used as surrogate endpoints in clinical trials.

\section{Screening high-risk subjects}

Although many attempts, including national publicity and various programs for health promotion, have been made to manage stroke risk factors, the prevalence of stroke has not been markedly reduced. This may be partially attributable to hidden risk factors of stroke. Interestingly, certain regions in the United States (Stroke Belt and Buckle) have an unusually high incidence and mortality of stroke and the phenomenon could not be explained by the differences of the conventional risk factors. ${ }^{12,13}$ The exact causes of the higher incidence and mortality of stroke in the regions have not been recognized. Therefore, many researchers have devoted themselves to find novel risk factors of stroke to explain it, whereupon numerous possible contributing factors have been identified, including obesity/metabolic syndrome, diet, sleep-related breathing disorders, air pollution, and cultural lifestyle. ${ }^{14}$

In addition to finding these new risk factors, a series of biomarkers reflecting inflammation, hemostasis, thrombosis, endothelial function, or neurohormonal activity have been evaluated as potential tools in an effort to improve risk prediction of future stroke, and thereby avert future events. ${ }^{15-22}$ For example, a recent investigation using data from the Framingham offspring study found that plasma asymmetrical dimethylarginine (ADMA) which is an inhibitor of endothelial nitric oxide synthase (eNOS) and a marker of endothelial dysfunction was associated with a prevalence of silent brain infarcts which is an important correlate of risk of future stroke. ${ }^{19}$ More recently, the same group published data on multiple biomarkers and identified that baseline B-type natriuretic peptide (BNP) having diuretic and vasodilatory activities and a urinary albumin/creatinine ratio indicating endothelial function were associated with the risk of incident stroke, and offered modest improvements in the accuracy of risk stratification. ${ }^{22}$ In the near future, a genome-wide association study may also greatly contribute to building risk stratification models by identifying genetic variants that confer susceptibility to cerebrovascular disease. ${ }^{23}$

\section{Rapid stroke diagnosis}

Although the diagnosis of acute stroke mostly relies on neuroimaging techniques, the evaluation of biomarkers of tissue injury would be an alternative strategy for rapid stroke assessment. This approach has already been successfully applied in the early management of other diseases including coronary heart disease (troponin, $\mathrm{CK}-\mathrm{MB})$, pulmonary embolism (D-dimer), and congestive heart failure (BNP). ${ }^{24-26} \mathrm{~A}$ rapid diagnosis of stroke based on biomarkers may be useful especially for pre-hospital screening, facilitating entry into a fast track care pathway, and for ancillary data when contemplating thrombolysis. However, a widely available, rapid, and sensitive diagnostic test for acute cerebral ischemia has not been available until now.

Recently, a biomarker panel rather than a single marker in isolation has been increasingly used to improve the diagnostic accuracy of suspected stroke. For instance, a diagnostic panel incorporating the levels of matrix metalloproteinase 9 (MMP9), BNP, D-dimer, and S-100 $\beta$ into a composite score enhanced sensitivity of early noncontrast CT alone for acute stroke, although the diagnostic accuracy was clearly imperfect. ${ }^{27}$ Furthermore, the approach was feasible as a point-of-care test in the emergency setting. ${ }^{27}$ As the number of presumed biomarkers for stroke expands at an exponential rate, it would be expected to develop improved biomarker combinations for more accurate diagnosis of stroke.

\section{Detection of possible stroke mechanisms}

Several studies have focused on the use of biomarkers for detecting possible stroke mechanisms. A recent study investigated whether concentrations of von Willebrand factor (vWF) which plays crucial roles in thrombus formation differ depending on the etiologic subtypes of stroke, and found the highest levels in large artery disease and cardioembolic stroke. ${ }^{28}$ Recent data by our group also demonstrated that inflammatory markers, rather than traditional risk factors were associated with clinical and radiological differences among patients with atherosclerotic stroke. ${ }^{29}$ In addition, the molecular markers related to neuronal death can provide information about the presence of tissue at risk of infarction. ${ }^{30,31}$

\section{Predicting drug response and outcome}

It has been well known that different patients respond in different manners to the same medication. Among many factors that influence the effects of drugs, it is estimated that genetic factors can account for 20 to $95 \%$ of variability in drug disposition and effects. ${ }^{32}$ For example, previous studies revealed that CYP2C9 and VKORC1 genetic variants are associated with warfarin dose requirement and clinical outcomes. ${ }^{33,34}$ Besides pharmacogenetics, several biomarkers are also contributing to predicting drug responses in patients with stroke, particularly when thrombolysis is administered. Specifically, elevated S-100 $\beta$ and MMP-9 which were reported as serum markers of bloodbrain barrier (BBB) dysfunction before thrombolysis could predict hemorrhagic transformation after thrombolysis, ${ }^{35-37}$ whereas baseline levels of $\alpha_{2}$-antiplasmin were predictive of recanalization in patients treated with rt-PA. ${ }^{38}$ 
There has been mounting evidence that a number of biomarkers can predict clinical or radiological outcomes from cerebral ischemic events. Inflammatory markers such as $\mathrm{C}$-reactive protein (CRP) or proinflammatory cytokines are reportedly associated with early neurological worsening or poor functional outcome after stroke. ${ }^{39,40}$ Biomarkers related to coagulation/fibrinolysis system such as D-dimer or vWF may also have links with outcome prediction, especially in patients with cardioembolic stroke. ${ }^{41-44}$ Very recently, it was reported that genetic polymorphisms of brain-derived neurotrophic factor (BDNF) was associated with functional outcome after subarachnoid hemorrhage, and cortical plasticity. ${ }^{45,46}$

\section{Surrogate endpoints in clinical trials}

In cardiovascular diseases, many investigators have used biomarkers that correlate with clinical outcomes as surrogate end- points, because event-driven clinical trials require much of the cost and time burden. ${ }^{47}$ In the area of stroke research, several studies has been started to use biomarkers to monitor the efficacy and safety of treatments in phase III clinical trials. However, changes detected in surrogate markers do not always translate into clinical endpoints, and may even be the opposite with clinical outcomes. ${ }^{48}$ Thus, biomarkers may be useful as a screening tool and secondary outcomes, but not primary outcome in clinical trials at the present time.

\section{Type of biomarkers in stroke research}

Stroke biomarkers include traditional protein biomarkers and novel genetic, microvesicle, and metabolomics-associated biomarkers (Table 2).

Table 2. Biomarkers for specific stroke subtypes

\begin{tabular}{|c|c|c|c|}
\hline & Protein & Genetic & Microvesicle \\
\hline Extracranial atherosclerosis & $\begin{array}{l}\text { Inflammation (CRP), coagulation/ fibrinolysis } \\
\text { (TAT, PIC, d-dimer })^{74} \\
\text { CRP29,51 }^{74} \\
\text { sP-selectin }^{75} \\
\text { Adioponectin }^{76} \\
\text { Homocysteine } \\
\text { Lipoprotein lipase }\end{array}$ & $\begin{array}{l}\text { CRP polymorphism }^{78} \\
\text { Fibrinogen polymorphism }{ }^{79} \\
\text { Several gene polymorphism (ABCA1, IRAK1, ROS1) } \\
\text { SOX6 gene on chr'11p15, 14q32, 15q2381 } \\
\text { Lipoprotein lipase }^{82} \\
\text { Genetic risk score on } 13 \text { SNPs ass. With MI/CAD }\end{array}$ & $\begin{array}{l}\text { Platelet-derived microvesicle }{ }^{84} \\
\text { Endothelial activation }^{85}\end{array}$ \\
\hline Intracranial atherosclerosis & 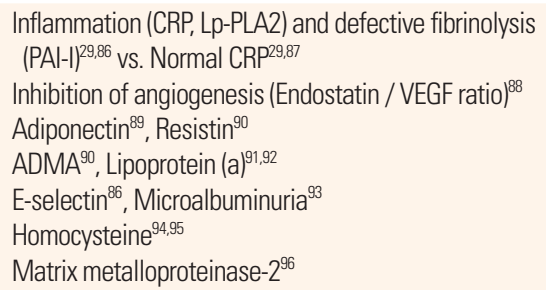 & $\begin{array}{l}\text { Adiponectin and insulin resistance polymorphism } \\
(\text { FABP2 })^{97} \\
\text { Lipoprotein lipase }^{82} \\
\text { CRP polymorphism }^{98} \text { vs. no association }\end{array}$ & Endothelial dysfunction ${ }^{85}$ \\
\hline Cardioembolic & $\begin{array}{l}\text { Combined model including clinical and biomarker } \\
(\text { BNP and d-dimer) })^{100} \\
\text { Thrombosis and fibrinolysis (TAT, AT-IIII, d-dimer) }{ }^{101} \\
\text { Endothelial damage and platelet activation } \\
\text { (vWF, sP-selectin) })^{72} \\
\text { Platelet activation (SCD40L) })^{102}\end{array}$ & $\begin{array}{l}\text { Risk variants for atrial fibrillation on chr'4q25 } \\
\text { associated with cardioembolic stroke }{ }^{103,104}\end{array}$ & $\begin{array}{l}\text { Platelet-derived microvesicle } \\
\text { in atrial fibrillation }\end{array}$ \\
\hline Small arterial & $\begin{array}{l}\text { Inflammation (CRP and IL-6) } \\
\text { Homocysteine } \\
\text { tPA activity \& PAI-1 level } \\
\text { ICAM } \\
\text { Microalbuminuria }\end{array}$ & $\begin{array}{l}\text { PKC (PRKCH) })^{107} \\
\text { Leukotriene } C 4 \text { synthase }^{108} \\
\text { IL-6 polymorphism }{ }^{106} \\
\text { Endothelin }{ }^{109} \\
\text { CADASIL and COL4A1 mutations }{ }^{110} \\
\text { No genetic association }{ }^{111}\end{array}$ & \\
\hline Cryptogenic & $\begin{array}{l}\text { Hypercoagulopathy }(\mathrm{F} 1.2)^{112} \\
\text { Hypercoagulopathy in cancer (d-dimer) })^{113-116}\end{array}$ & & Hypercoagulopathy in cancer ${ }^{117}$ \\
\hline Hemorrhagic & Matrix metalloproteinase-965 & $\begin{array}{l}\text { Several gene polymorphism (LIMK1, CYP3A4) } \\
\text { No association of tPA-related complication and } \\
\text { MMPg'118 }\end{array}$ & $\begin{array}{l}\text { Endothelial microvesicle in } \\
\text { subarachnoid hemorrhage }^{119}\end{array}$ \\
\hline
\end{tabular}

TAT, Thrombin-Antithrombin complex; PIC, Plasmin inhibitor complex; sP-selectin, Soluble P-selectin; ABCA1, ATP-binding cassette, subfamily A, member 1; IRAK1, Interleukin-1 receptor-associated kinase-1; ROS1, v-Ros avian UR2 sarcoma virus oncogene homolog-1; SOX6, sex-determining region Y-box 6; SNP, Single nucleotide polymorphism; MI, Myocardial infarction; CAD, Coronary artery disease; CRP, C-reactive protein; Lp-PLA2, Lipoprotein-associated phospholipase A2; PAI-1, Plasminogen activator inhibitor-1; VEGF, Vascular endothelial growth factor; ADMA, Asymmetrical dimethylarginine; FABP2, Fatty acid-binding protein 2; BNP, B-type natriuretic peptide; AT-III, Antithrombin-III; vWF, von Willebrand factor; sCD40L, Soluble CD40 ligand; tPA, Tissue plasminogen activator; ICAM, Intercellular adhesion molecule; PKC, Protein kinase C; PRKCH, Protein kinase C eta; CADASIL, Cerebral autosomal dominant arteriopathy with subcortical infarcts and leukoencephalopathy; COL4A1, Collagen, type IV, alpha 1; F1.2, Prothrombin fragment 1.2; LIMK1, LIM domain kinase 1; CYP3A4, Cytochrome P450, subfamily IIIA, polypeptide 4. 


\section{Protein biomarkers}

Research using protein biomarkers in patients with ischemic cerebrovascular disease have mainly focused on pathophysiology, diagnosis, prognostication, and neuronal death in stroke. ${ }^{49} \mathrm{~A}$ typical example of protein biomarkers is CRP. ${ }^{17,50,51}$ However, a recent study raised the possibility that the relation may result from various biases. ${ }^{52}$ Moreover, it has raised skepticism about the efficacy of biomarkers in predicting stroke risk because they provide only limited additional information compared to the well-known stroke risk factors. ${ }^{53,54}$ Further studies with more a systematic approach and analysis are needed in this area.

\section{Genetic biomarkers}

Many epidemiological studies suggested that stroke has genetic susceptibility, and various genetic factors were investigated. ${ }^{55}$ Among them, establishing the association of the 9p21.3 locus with risk of cerebral infarction is one of the biggest advances. ${ }^{56} \mathrm{It}$ is estimated that the genetic influence is caused by enhanced platelet reactivity. ${ }^{56}$ However, many other genomewide association studies failed to reproduce the positive results obtained from previous studies ${ }^{57}$ or have shown that the clinical usefulness was very low. ${ }^{58}$ For example, the hazard ratio and population attributable risk of hypertension to ischemic stroke is 2.0 and $26 \%$, respectively. Conversely, the genetic influence on stroke was only $1.3-1.33$ and $11-12 \%$, respectively. ${ }^{58}$

Recently, studies in the pharmacogenomic area have been actively carried out. Among them, aspirin, clopidogrel, warfarin, statin, and thrombolytics-related genetic polymorphisms are particularly of interest. It is expected that selecting the type or dose of medication, avoiding side effects, or drug resistance may be guided by simple genetic tests in the near future.

\section{Microvesicle}

Microvesicles are defined as a heterogeneous population of small vesicles with a diameter of $0.1-1 \mu \mathrm{m}$. It was previously believed that microvesicles were artifacts generated by apoptotic cell death. However, this view has changed because the shedding of these small vesicles was recognized to result from an active process..$^{59}$ Microvesicles may be a window for target cell/ organs, and include genetic information as well as protein inside them. ${ }^{60}$ Moreover, it has been identified that microvesicles have their own function, revealing that microvesicles from ischemic tissue facilitated vasculogenesis in the ischemic limb model. ${ }^{61}$ In this regard, biomarker research using microvesicles is a prominent field.

Nevertheless, biomarker studies using microvesicles in stroke are mostly performed in small cohorts. As the methods for analyzing microvesicles are complicated and not unique mainly due to their very small size, investigations with microvesicles are currently at a rudimentary state of development. When seeing the results from a large-scale clinical study perspective for the prediction of the future risk of myocardial infarction, microvesicles could be a good candidate to compensate for the limitations of existing biomarker researches. ${ }^{62}$

\section{Metabolomics}

The assumption of metabolomics is that occurrence of the disease is directly related to the specific change of biochemical composition in the cell or biological fluid. Metabolomics-associated biomarker research analyzes profiles of fatty acids, amino acids, or polyamine in the blood or urine and determines normal or pathologic states. Furthermore, metabolomics-associated biomarkers can be applied to the monitoring recovery after treatment. Unfortunately, studies using metabolomics in the area of stroke is relatively lacking.

\section{Limitations of stroke biomarkers}

Currently, the application of biomarkers in the management of cerebral infarction has some limitations, despite their evolving role.

First, unlike myocardial infarction, changes in the brain are not sufficiently reflected by blood biomarkers due to the presence of the blood-brain barrier (low sensitivity and underpowered).

Second, biomarkers can change by a variety of comorbid conditions or brain damage itself (confounders and lack of specificities). As asymptomatic coronary atherosclerosis is frequently accompanied in patients with ischemic stroke, ${ }^{63}$ it may confound the levels of biomarkers. Indeed, our group recently found that the burden of asymptomatic coronary atherosclerosis was the most important factor for levels of $\mathrm{C}$-reactive protein and homocysteine, regardless of vascular risk factors and the degree and distribution of cervicocephalic atherosclerosis (Figure 1) ${ }^{64}$ Furthermore, the direct role of biomarkers in the disease process may be hard to reveal. For example, matrix metalloproteinase-9 (MMP-9) which is known as a marker of hemorrhagic transformation after thrombolysis ${ }^{65}$ is significantly associated with the size of the cerebral infarction irrespective of hemorrhagic transformation. ${ }^{29}$ Therefore, it is difficult to establish the causal relationship between biomarkers and ischemic stroke in a real clinical setting.

Third, there is no sufficiently robust single marker for stroke. As shown in Table 2, ischemic stroke is a complex process that includes various etiologies. In addition, the brain consists of many different cells with vessels having distinct anatomical char- 


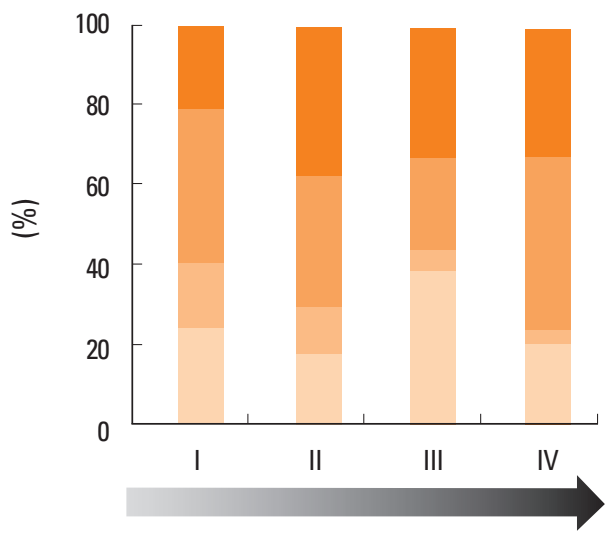

Severity of cerebral artery atherosclerosis
Quartiles of CRP values

- Quartile 4

- Quartile 3

- Quartile 2

- Quartile 1

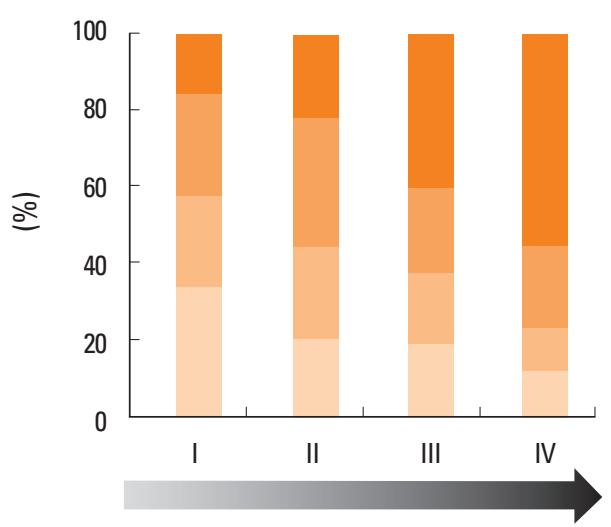

Asymptomatic burden of coronary artery atherosclerosis

Figure 1. Distribution of CRP according to the (A) severity of cerebral atherosclerosis or $(B)$ asymptomatic burden of coronary atherosclerosis in patients with stroke. CRP values are proportional to the increase of coronary ( $P=0.010$ for trends), but not cerebral atherosclerosis ( $P=0.131$ for trends). Severity of cerebral or coronary atherosclerosis. I: No atherosclerosis or 1 segment with $<50 \%$ stenosis, II: $\geq 2$ segments with $<50 \%$ stenosis, III: 1 segment with $\geq 50 \%$ stenosis, IV: $\geq 2$ segments with $\geq 50 \%$ stenosis.

Table 3. Strengths and weaknesses of various biomarkers

\begin{tabular}{lll}
\hline & Advantage & Disadvantage \\
\hline Protein & "Post-stroke analysis" & Time-dependent (snapshot $\rightarrow$ need serial checking) \\
& Gene-environment interaction & Small numbers of final products (not causative in most) \\
Quantitation & \\
Gene & "Pre-stroke screening" & Influence of environment (> gene) on the development of most disease (polygenic) \\
& Automatism & Recent failures to reproduce results \\
Microvesicle & Slentiful candidate & \\
& Similar to protein biomarkers & Similar to protein biomarkers \\
& Functional (it contains nucleic components as well as trophic factors & Methods for measurement - unsettled \\
& May causative & Effortful \\
Window for not only damaged but also intact cells and tissues & Limited and non-specific markers for identification of microvesicles
\end{tabular}

acteristics.

\section{Future direction and summary: need of comprehensive approach}

Each biomarker has different aspects, and its own advantages and drawbacks (Table 3). Therefore, developing an integrated panel of biomarkers for specific stroke subtypes is needed. A recent study reported that multiple microparticle biomarkers in addition to existing protein biomarkers are valuable for predicting future cardio- and cerebrovascular events. ${ }^{62}$ Hence, a comprehensive approach to using a variety of biomarkers is warranted to overcome the limitations. In addition, multidisciplinary approaches including neuroimaging biomarkers are needed.

A number of biomarkers are under investigation in patients with ischemic stroke. Research about biomarkers can be helpful especially in predicting stroke and monitoring therapeutic effects. Currently, however, the application of biomarkers is only recommended for research purposes. Monitoring traditional risk factors or vessel status is more efficacious than measuring biomarkers in clinical practice. Considering the advantages and disadvantages of each biomarker is important for future study, and a comprehensive approach using multiple biomarkers is needed. It is strongly anticipated that the biomarkers can provide us a turning point for investigating pathophysiology and therapeutic mechanisms of ischemic stroke.

\section{References}

1. Chimowitz MI, Lynn MJ, Howlett-Smith H, Stern BJ, Hertzberg VS, Frankel MR, et al. Comparison of warfarin and aspirin for symptomatic intracranial arterial stenosis. $N$ Engl J Med 2005;352:1305-1316.

2. Diener HC, Bogousslavsky J, Brass LM, Cimminiello C, Csiba L, Kaste M, et al. Aspirin and clopidogrel compared with clopidogrel alone after recent ischaemic stroke or transient ischaemic attack in high-risk patients (MATCH): randomised, double-blind, placebo-controlled trial. Lancet 2004;364:331- 
337.

3. Bhatt DL, Fox KA, Hacke W, Berger PB, Black HR, Boden $\mathrm{WE}$, et al. Clopidogrel and aspirin versus aspirin alone for the prevention of atherothrombotic events. N Engl J Med 2006; 354:1706-1717.

4. Hacke W, Furlan AJ, Al-Rawi Y, Davalos A, Fiebach JB, Gruber $\mathrm{F}$, et al. Intravenous desmoteplase in patients with acute ischaemic stroke selected by MRI perfusion-diffusion weighted imaging or perfusion CT (DIAS-2): a prospective, randomised, double-blind, placebo-controlled study. Lancet Neurol 2009;8:141-150.

5. Davis SM, Donnan GA, Parsons MW, Levi C, Butcher KS, Peeters A, et al. Effects of alteplase beyond $3 \mathrm{~h}$ after stroke in the Echoplanar Imaging Thrombolytic Evaluation Trial (EPITHET): a placebo-controlled randomised trial. Lancet Neurol 2008;7:299-309.

6. Shuaib A, Lees KR, Lyden P, Grotta J, Davalos A, Davis SM, et al. NXY-059 for the treatment of acute ischemic stroke. $N$ Engl J Med 2007;357:562-571.

7. Albers GW, Goldstein LB, Hess DC, Wechsler LR, Furie KL, Gorelick PB, et al. Stroke Treatment Academic Industry Roundtable (STAIR) recommendations for maximizing the use of intravenous thrombolytics and expanding treatment options with intra-arterial and neuroprotective therapies. Stroke 2011; 42:2645-2650.

8. Schulz KF, Altman DG, Moher D. CONSORT 2010 statement: updated guidelines for reporting parallel group randomised trials. PLoS Med 2010; 7:e1000251.

9. Maasland L, van Oostenbrugge RJ, Franke CF, Scholte Op Reimer WJ, Koudstaal PJ, Dippel DW. Patients enrolled in large randomized clinical trials of antiplatelet treatment for prevention after transient ischemic attack or ischemic stroke are not representative of patients in clinical practice: the Netherlands Stroke Survey. Stroke 2009;40:2662-2668.

10. Saver JL. Novel end point analytic techniques and interpreting shifts across the entire range of outcome scales in acute stroke trials. Stroke 2007;38:3055-3062.

11. Saver JL, Gornbein J. Treatment effects for which shift or binary analyses are advantageous in acute stroke trials. Neurology 2009;72:1310-1315.

12. Casper ML, Wing S, Anda RF, Knowles M, Pollard RA. The shifting stroke belt. Changes in the geographic pattern of stroke mortality in the United States, 1962 to 1988. Stroke 1995;26: 755-760.

13. El-Saed A, Kuller LH, Newman AB, Lopez O, Costantino J, McTigue $\mathrm{K}$, et al. Geographic variations in stroke incidence and mortality among older populations in four US communities. Stroke 2006;37:1975-1979.
14. Howard G, Prineas R, Moy C, Cushman M, Kellum M, Temple $\mathrm{E}$, et al. Racial and geographic differences in awareness, treatment, and control of hypertension: the REasons for Geographic And Racial Differences in Stroke study. Stroke 2006; 37:1171-1178.

15. Ridker PM, Brown NJ, Vaughan DE, Harrison DG, Mehta JL. Established and emerging plasma biomarkers in the prediction of first atherothrombotic events. Circulation 2004;109:IV6-19.

16. Woodward M, Lowe GD, Campbell DJ, Colman S, Rumley A, Chalmers J, et al. Associations of inflammatory and hemostatic variables with the risk of recurrent stroke. Stroke 2005; 36:2143-2147.

17. Ridker PM, Danielson E, Fonseca FA, Genest J, Gotto AM Jr, Kastelein JJ, et al. Rosuvastatin to prevent vascular events in men and women with elevated C-reactive protein. $N$ Engl J Med 2008;359:2195-2207.

18. Welsh P, Lowe GD, Chalmers J, Campbell DJ, Rumley A, Neal $\mathrm{BC}$, et al. Associations of proinflammatory cytokines with the risk of recurrent stroke. Stroke 2008;39:2226-2230.

19. Pikula A, Boger RH, Beiser AS, Maas R, DeCarli C, Schwedhelm E, et al. Association of plasma ADMA levels with MRI markers of vascular brain injury: Framingham offspring study. Stroke 2009;40:2959-2964.

20. Park CS, Ihm SH, Yoo KD, Kim DB, Lee JM, Kim HY, et al. Relation between C-reactive protein, homocysteine levels, fibrinogen, and lipoprotein levels and leukocyte and platelet counts, and 10-year risk for cardiovascular disease among healthy adults in the USA. Am J Cardiol 2010;105:1284-1288.

21. Wieberdink RG, van Schie MC, Koudstaal PJ, Hofman A, Witteman JC, de Maat MP, et al. High von Willebrand factor levels increase the risk of stroke: the Rotterdam study. Stroke 2010; 41:2151-2156.

22. Pikula A, Beiser AS, DeCarli C, Himali JJ, Debette S, Au R, et al. Multiple biomarkers and risk of clinical and subclinical vascular brain injury: the Framingham Offspring Study. Circulation 2012;125:2100-2107.

23. Yamada Y, Fuku N, Tanaka M, Aoyagi Y, Sawabe M, Metoki $\mathrm{N}$, et al. Identification of CELSR1 as a susceptibility gene for ischemic stroke in Japanese individuals by a genome-wide association study. Atherosclerosis 2009;207:144-149.

24. Penttila K, Koukkunen H, Halinen M, Rantanen T, Pyorala $\mathrm{K}$, Punnonen K, et al. Myoglobin, creatine kinase MB isoforms and creatine kinase $\mathrm{MB}$ mass in early diagnosis of myocardial infarction in patients with acute chest pain. Clin Biochem 2002; 35:647-653.

25. Gibler WB, Blomkalns AL, Collins SP. Evaluation of chest pain and heart failure in the emergency department: impact of multimarker strategies and b-type natriuretic peptide. Rev Cardio- 
vasc Med 2003;4 (Suppl 4):S47-55.

26. Stein PD, Hull RD, Patel KC, Olson RE, Ghali WA, Brant R, et al. D-dimer for the exclusion of acute venous thrombosis and pulmonary embolism: a systematic review. Ann Intern Med 2004; 140:589-602.

27. Laskowitz DT, Kasner SE, Saver J, Remmel KS, Jauch EC. Clinical usefulness of a biomarker-based diagnostic test for acute stroke: the Biomarker Rapid Assessment in Ischemic Injury (BRAIN) study. Stroke 2009;40:77-85.

28. Hanson E, Jood K, Karlsson S, Nilsson S, Blomstrand C, Jern C. Plasma levels of von Willebrand factor in the etiologic subtypes of ischemic stroke. J Thromb Haemost 2011;9:275-281.

29. Bang OY, Lee PH, Yoon SR, Lee MA, Joo IS, Huh K. Inflammatory markers, rather than conventional risk factors, are different between carotid and MCA atherosclerosis. J Neurol Neurosurg Psychiatry 2005;76:1128-1134.

30. Rodriguez-Yanez M, Sobrino T, Arias S, Vazquez-Herrero F, Brea D, Blanco M, et al. Early biomarkers of clinical-diffusion mismatch in acute ischemic stroke. Stroke 2011;42:2813-2818.

31. Kernagis DN, Laskowitz DT. Evolving role of biomarkers in acute cerebrovascular disease. Ann Neurol 2012;71:289-303.

32. Kalow W, Tang BK, Endrenyi L. Hypothesis: comparisons of inter- and intra-individual variations can substitute for twin studies in drug research. Pharmacogenetics 1998;8:283-289.

33. Higashi MK, Veenstra DL, Kondo LM, Wittkowsky AK, Srinouanprachanh SL, Farin FM, et al. Association between CYP2C9 genetic variants and anticoagulation-related outcomes during warfarin therapy. JAMA 2002;287:1690-1698.

34. Sconce EA, Khan TI, Wynne HA, Avery P, Monkhouse L, King BP, et al. The impact of CYP2C9 and VKORC1 genetic polymorphism and patient characteristics upon warfarin dose requirements: proposal for a new dosing regimen. Blood 2005; 106:2329-2333.

35. Heo JH, Kim SH, Lee KY, Kim EH, Chu CK, Nam JM. Increase in plasma matrix metalloproteinase-9 in acute stroke patients with thrombolysis failure. Stroke 2003;34:e48-50.

36. Montaner J, Molina CA, Monasterio J, Abilleira S, Arenillas JF, Ribo M, et al. Matrix metalloproteinase-9 pretreatment level predicts intracranial hemorrhagic complications after thrombolysis in human stroke. Circulation 2003;107:598-603.

37. Foerch C, Wunderlich MT, Dvorak F, Humpich M, Kahles T, Goertler M, et al. Elevated serum S100B levels indicate a higher risk of hemorrhagic transformation after thrombolytic therapy in acute stroke. Stroke 2007;38:2491-2495.

38. Marti-Fabregas J, Borrell M, Cocho D, Belvis R, Castellanos $\mathrm{M}$, Montaner J, et al. Hemostatic markers of recanalization in patients with ischemic stroke treated with rt-PA. Neurology 2005;65:366-370.
39. Vila N, Castillo J, Davalos A, Chamorro A. Proinflammatory cytokines and early neurological worsening in ischemic stroke. Stroke 2000;31:2325-2329.

40. Whiteley W, Jackson C, Lewis S, Lowe G, Rumley A, Sandercock $\mathrm{P}$, et al. Inflammatory markers and poor outcome after stroke: a prospective cohort study and systematic review of interleukin-6. PLoS Med 2009;6:e1000145.

41. Yoon CW, Kim SJ, Bang OY, Chung CS, Lee KH, Kim GM. Premorbid warfarin use and lower D-dimer levels are associated with spontaneous early improvement in atrial fibrillationrelated stroke. J Thromb Haemost 2012. (doi: 10.1111/j.15387836.2012.04909.x.)

42. Roldan V, Marin F, Muina B, Torregrosa JM, Hernandez-Romero D, Valdes M, et al. Plasma von Willebrand factor levels are an independent risk factor for adverse events including mortality and major bleeding in anticoagulated atrial fibrillation patients. J Am Coll Cardiol 2011;57:2496-2504.

43. Motoki H, Tomita T, Aizawa K, Kasai H, Izawa A, Kumazaki $S$, et al. Coagulation activity is increased in the left atria of patients with paroxysmal atrial fibrillation during the non-paroxysmal period. Comparison with chronic atrial fibrillation. Circ J2009;73:1403-1407.

44. Kang DW, Yoo SH, Chun S, Kwon KY, Kwon SU, Koh JY, et al. Inflammatory and hemostatic biomarkers associated with early recurrent ischemic lesions in acute ischemic stroke. Stroke 2009;40:1653-1658.

45. Siironen J, Juvela S, Kanarek K, Vilkki J, Hernesniemi J, Lappalainen J. The Met allele of the BDNF Val66Met polymorphism predicts poor outcome among survivors of aneurysmal subarachnoid hemorrhage. Stroke 2007;38:2858-2860.

46. Cheeran B, Talelli P, Mori F, Koch G, Suppa A, Edwards M, et al. A common polymorphism in the brain-derived neurotrophic factor gene (BDNF) modulates human cortical plasticity and the response to rTMS. J Physiol 2008;586:5717-5725.

47. Halim SA, Newby LK, Ohman EM. Biomarkers in cardiovascular clinical trials: past, present, future. Clin Chem 2012;58: 45-53.

48. Echt DS, Liebson PR, Mitchell LB, Peters RW, Obias-Manno $\mathrm{D}$, Barker AH, et al. Mortality and morbidity in patients receiving encainide, flecainide, or placebo. The Cardiac Arrhythmia Suppression Trial. N Engl J Med 1991;324:781-788.

49. Lynch JR, Blessing R, White WD, Grocott HP, Newman MF, Laskowitz DT. Novel diagnostic test for acute stroke. Stroke 2004;35:57-63.

50. Ridker PM, Cushman M, Stampfer MJ, Tracy RP, Hennekens $\mathrm{CH}$. Inflammation, aspirin, and the risk of cardiovascular disease in apparently healthy men. N Engl J Med 1997;336:973979. 
51. Van Der Meer IM, De Maat MP, Hak AE, Kiliaan AJ, Del Sol AI, Van Der Kuip DA, et al. C-reactive protein predicts progression of atherosclerosis measured at various sites in the arterial tree: the Rotterdam study. Stroke 2002;33:2750-2755.

52. Hemingway H, Philipson P, Chen R, Fitzpatrick NK, Damant J, Shipley M, et al. Evaluating the quality of research into a single prognostic biomarker: a systematic review and meta-analysis of 83 studies of C-reactive protein in stable coronary artery disease. PLoS Med 2010; 7:e1000286.

53. Hankey GJ. Potential new risk factors for ischemic stroke: what is their potential? Stroke 2006;37:2181-2188.

54. O’Donnell MJ, Xavier D, Liu L, Zhang H, Chin SL, Rao-Melacini $\mathrm{P}$, et al. Risk factors for ischaemic and intracerebral haemorrhagic stroke in 22 countries (the INTERSTROKE study): a case-control study. Lancet 2010;376:112-123.

55. Dichgans M. Genetics of ischaemic stroke. Lancet Neurol 2007; 6:149-161.

56. Meschia JF. Advances in genetics 2010. Stroke 2011;42:285287.

57. Lanktree MB, Dichgans M, Hegele RA. Advances in genomic analysis of stroke: what have we learned and where are we headed? Stroke 2010;41:825-832.

58. Ikram MA, Seshadri S, Bis JC, Fornage M, DeStefano AL, Aulchenko YS, et al. Genomewide association studies of stroke. $N$ Engl J Med 2009;360:1718-1728.

59. Cocucci E, Racchetti G, Meldolesi J. Shedding microvesicles: artefacts no more. Trends Cell Biol 2009;19:43-51.

60. Kim SJ, Moon GJ, Cho YH, Kang HY, Hyung NK, Kim D, et al. Circulating mesenchymal stem cells microparticles in patients with cerebrovascular disease. PLoS One 2012; 7:e37036.

61. Leroyer AS, Ebrahimian TG, Cochain C, Recalde A, BlancBrude $\mathrm{O}$, Mees $\mathrm{B}$, et al. Microparticles from ischemic muscle promotes postnatal vasculogenesis. Circulation 2009; 119:28082817.

62. Nozaki T, Sugiyama S, Koga H, Sugamura K, Ohba K, Matsuzawa $Y$, et al. Significance of a multiple biomarkers strategy including endothelial dysfunction to improve risk stratification for cardiovascular events in patients at high risk for coronary heart disease. J Am Coll Cardiol 2009;54:601-608.

63. Calvet D, Touze E, Varenne O, Sablayrolles JL, Weber S, Mas JL. Prevalence of asymptomatic coronary artery disease in ischemic stroke patients: the PRECORIS study. Circulation 2010;121:1623-1629.

64. Kim SJ, Choe YH, Bang OY. Are stroke biomarkers seeing brain vessels in patients with ischemic stroke? A C-reactive protein and homocysteine study. Stroke 2011;42:1464-1468.

65. Castellanos M, Sobrino T, Millan M, Garcia M, Arenillas J, Nombela F, et al. Serum cellular fibronectin and matrix metal- loproteinase- 9 as screening biomarkers for the prediction of parenchymal hematoma after thrombolytic therapy in acute ischemic stroke: a multicenter confirmatory study. Stroke 2007; 38:1855-1859.

66. Reynolds MA, Kirchick HJ, Dahlen JR, Anderberg JM, McPherson PH, Nakamura KK, et al. Early biomarkers of stroke. Clin Chem 2003;49:1733-1739.

67. Jauch EC, Lindsell C, Broderick J, Fagan SC, Tilley BC, Levine SR. Association of serial biochemical markers with acute ischemic stroke: the National Institute of Neurological Disorders and Stroke recombinant tissue plasminogen activator Stroke Study. Stroke 2006;37:2508-2513.

68. Montaner J, Rovira A, Molina CA, Arenillas JF, Ribo M, Chacon $\mathrm{P}$, et al. Plasmatic level of neuroinflammatory markers predict the extent of diffusion-weighted image lesions in hyperacute stroke. J Cereb Blood Flow Metab 2003;23:1403-1407.

69. Iwamoto T, Kubo H, Takasaki M. Platelet activation in the cerebral circulation in different subtypes of ischemic stroke and Binswanger's disease. Stroke 1995;26:52-56.

70. Matsui T, Mori T, Tateishi N, Kagamiishi Y, Satoh S, Katsube $\mathrm{N}$, et al. Astrocytic activation and delayed infarct expansion after permanent focal ischemia in rats. Part I: enhanced astrocytic synthesis of s-100beta in the periinfarct area precedes delayed infarct expansion. J Cereb Blood Flow Metab 2002;22: 711-722.

71. Foerch C, du Mesnil de Rochemont R, Singer O, NeumannHaefelin T, Buchkremer M, Zanella FE, et al. S100B as a surrogate marker for successful clot lysis in hyperacute middle cerebral artery occlusion. J Neurol Neurosurg Psychiatry 2003; 74:322-325.

72. Conway DS, Pearce LA, Chin BS, Hart RG, Lip GY. Prognostic value of plasma von Willebrand factor and soluble P-selectin as indices of endothelial damage and platelet activation in 994 patients with nonvalvular atrial fibrillation. Circulation 2003; 107:3141-3145.

73. Rost NS, Biffi A, Cloonan L, Chorba J, Kelly P, Greer D, et al. Brain natriuretic peptide predicts functional outcome in ischemic stroke. Stroke 2012;43:441-445.

74. Tohgi H, Konno S, Takahashi S, Koizumi D, Kondo R, Takahashi $\mathrm{H}$. Activated coagulation/fibrinolysis system and platelet function in acute thrombotic stroke patients with increased C-reactive protein levels. Thromb Res 2000;100:373-379.

75. Yip HK, Lu CH, Yang CH, Chang HW, Hung WC, Cheng CI, et al. Levels and value of platelet activity in patients with severe internal carotid artery stenosis. Neurology 2006;66:804808.

76. Barseghian A, Gawande D, Bajaj M. Adiponectin and vulnerable atherosclerotic plaques. J Am Coll Cardiol 2011;57:761- 
770.

77. Kim SJ, Song P, Park JH, Lee YT, Kim WS, Park YG, et al. Biomarkers of asymptomatic carotid stenosis in patients undergoing coronary artery bypass grafting. Stroke 2011;42:734739.

78. Zacho J, Tybjaerg-Hansen A, Jensen JS, Grande P, Sillesen H, Nordestgaard BG. Genetically elevated C-reactive protein and ischemic vascular disease. N Engl J Med 2008;359:1897-1908.

79. Tosetto A, Prati P, Baracchini C, Manara R, Rodeghiero F. Association of plasma fibrinogen, C-reactive protein and G-455>A polymorphism with early atherosclerosis in the VITA Project cohort. Thromb Haemost 2011; 105:329-335.

80. Yamada Y, Metoki N, Yoshida H, Satoh K, Kato K, Hibino T, et al. Genetic factors for ischemic and hemorrhagic stroke in Japanese individuals. Stroke 2008;39:2211-2218.

81. Dong C, Beecham A, Slifer S, Wang L, Blanton SH, Wright $\mathrm{CB}$, et al. Genomewide linkage and peakwide association analyses of carotid plaque in Caribbean Hispanics. Stroke 2010;41: 2750-2756.

82. Wang C, Sun T, Li H, Bai J, Li Y. Lipoprotein lipase Ser447Ter polymorphism associated with the risk of ischemic stroke: a meta-analysis. Thromb Res 2011;128:e107-112.

83. Hamrefors V, Hedblad B, Engstrom G, Almgren P, Sjogren M, Melander O. A myocardial infarction genetic risk score is associated with markers of carotid atherosclerosis. J Intern Med 2012;271:271-281.

84. Kuriyama N, Nagakane Y, Hosomi A, Ohara T, Kasai T, Harada $S$, et al. Evaluation of factors associated with elevated levels of platelet-derived microparticles in the acute phase of cerebral infarction. Clin Appl Thromb Hemost 2010;16:26-32.

85. Jung KH, Chu K, Lee ST, Park HK, Bahn JJ, Kim DH, et al. Circulating endothelial microparticles as a marker of cerebrovascular disease. Ann Neurol 2009;66:191-199.

86. Arenillas JF, Alvarez-Sabin J, Molina CA, Chacon P, Fernandez-Cadenas I, Ribo M, et al. Progression of symptomatic intracranial large artery atherosclerosis is associated with a proinflammatory state and impaired fibrinolysis. Stroke 2008;39: 1456-1463.

87. Takahashi W, Ohnuki T, Ohnuki Y, Kawada S, Takagi S. The role of high-sensitivity C-reactive protein in asymptomatic intra- and extracranial large artery diseases. Cerebrovasc Dis 2008; 26:549-555.

88. Arenillas JF, Alvarez-Sabin J, Montaner J, Rosell A, Molina CA, Rovira A, et al. Angiogenesis in symptomatic intracranial atherosclerosis: predominance of the inhibitor endostatin is related to a greater extent and risk of recurrence. Stroke 2005; 36:92-97.

89. Bang OY, Saver JL, Ovbiagele B, Choi YJ, Yoon SR, Lee KH.
Adiponectin levels in patients with intracranial atherosclerosis. Neurology 2007;68:1931-1937.

90. Lopez-Cancio E, Galan A, Dorado L, Jimenez M, Hernandez M, Millan M, et al. Biological Signatures of Asymptomatic Extra- and Intracranial Atherosclerosis: The Barcelona-AsIA (Asymptomatic Intracranial Atherosclerosis) Study. Stroke 2012;43:2712-2719.

91. Kim BS, Jung HS, Bang OY, Chung CS, Lee KH, Kim GM. Elevated serum lipoprotein(a) as a potential predictor for combined intracranial and extracranial artery stenosis in patients with ischemic stroke. Atherosclerosis 2010;212:682-688.

92. Arenillas JF, Molina CA, Chacon P, Rovira A, Montaner J, Coscojuela $\mathrm{P}$, et al. High lipoprotein (a), diabetes, and the extent of symptomatic intracranial atherosclerosis. Neurology 2004; 63:27-32.

93. Bang OY. Intracranial atherosclerotic stroke: specific focus on the metabolic syndrome and inflammation. Curr Atheroscler Rep 2006;8:330-336.

94. Huang YC, Kuo YW, Lee TH, Lee M, Hsiao MC, Wang CL, et al. Hypoalbuminemia and not hyperhomocysteinemia as a risk factor for dementia in hemodialysis patients. J Ren Nutr 2008; 18:347-354.

95. Yoo JH, Chung CS, Kang SS. Relation of plasma homocyst(e) ine to cerebral infarction and cerebral atherosclerosis. Stroke 1998;29:2478-2483.

96. Jeon SB, Chun S, Choi-Kwon S, Chi HS, Nah HW, Kwon SU, et al. Biomarkers and location of atherosclerosis: matrix metalloproteinase- 2 may be related to intracranial atherosclerosis. Atherosclerosis 2012;223:442-447.

97. Yamada Y, Kato K, Oguri M, Yoshida T, Yokoi K, Watanabe S, et al. Association of genetic variants with atherothrombotic cerebral infarction in Japanese individuals with metabolic syndrome. Int J Mol Med 2008;21:801-808.

98. Arenillas JF, Massot A, Alvarez-Sabin J, Fernandez-Cadenas I, del Rio-Espinola A, Chacon $\mathrm{P}$, et al. C-reactive protein gene C1444T polymorphism and risk of recurrent ischemic events in patients with symptomatic intracranial atherostenoses. Cerebrovasc Dis 2009;28:95-102.

99. Liu ZZ, Lv H, Gao F, Liu G, Zheng HG, Zhou YL, et al. Polymorphism in the human $\mathrm{C}$-reactive protein (CRP) gene, serum concentrations of CRP, and the difference between intracranial and extracranial atherosclerosis. Clin Chim Acta 2008; 389:40-44.

100. Montaner J, Perea-Gainza M, Delgado P, Ribo M, Chacon P, Rosell A, et al. Etiologic diagnosis of ischemic stroke subtypes with plasma biomarkers. Stroke 2008;39:2280-2287.

101. Kataoka S, Hirose G, Hori A, Shirakawa T, Saigan T. Activation of thrombosis and fibrinolysis following brain infarction. 
J Neurol Sci 2000; 181:82-88.

102. Ferro D, Loffredo L, Polimeni L, Fimognari F, Villari P, Pignatelli $\mathrm{P}$, et al. Soluble CD40 ligand predicts ischemic stroke and myocardial infarction in patients with nonvalvular atrial fibrillation. Arterioscler Thromb Vasc Biol 2007;27:2763-2768.

103. Gretarsdottir S, Thorleifsson G, Manolescu A, Styrkarsdottir U, Helgadottir A, Gschwendtner A, et al. Risk variants for atrial fibrillation on chromosome 4q25 associate with ischemic stroke. Ann Neurol 2008;64:402-409.

104. Lemmens R, Buysschaert I, Geelen V, Fernandez-Cadenas I, Montaner J, Schmidt H, et al. The association of the $4 \mathrm{q} 25$ susceptibility variant for atrial fibrillation with stroke is limited to stroke of cardioembolic etiology. Stroke 2010;41:1850-1857.

105. Choudhury A, Chung I, Blann AD, Lip GY. Elevated platelet microparticle levels in nonvalvular atrial fibrillation: relationship to p-selectin and antithrombotic therapy. Chest 2007;131: 809-815.

106. Fornage M, Chiang YA, O’Meara ES, Psaty BM, Reiner AP, Siscovick DS, et al. Biomarkers of inflammation and MRI-defined small vessel disease of the brain: The Cardiovascular Health Study. Stroke 2008;39:1952-1959.

107. Kubo M, Hata J, Ninomiya T, Matsuda K, Yonemoto K, Nakano T, et al. A nonsynonymous SNP in PRKCH (protein kinase $\mathrm{C}$ eta) increases the risk of cerebral infarction. Nat Genet 2007;39:212-217.

108. Bevan S, Dichgans M, Wiechmann HE, Gschwendtner A, Meitinger T, Markus HS. Genetic variation in members of the leukotriene biosynthesis pathway confer an increased risk of ischemic stroke: a replication study in two independent populations. Stroke 2008;39:1109-1114.

109. Gormley K, Bevan S, Hassan A, Markus HS. Polymorphisms in genes of the endothelin system and cerebral small-vessel disease. Stroke 2005;36:1656-1660.

110. Lanfranconi S, Markus HS. COL4A1 mutations as a monogenic cause of cerebral small vessel disease: a systematic review. Stroke 2010;41:e513-518.
111. Paternoster L, Chen W, Sudlow CL. Genetic determinants of white matter hyperintensities on brain scans: a systematic assessment of 19 candidate gene polymorphisms in 46 studies in 19,000 subjects. Stroke 2009;40:2020-2026.

112. Di Tullio MR, Homma S, Jin Z, Sacco RL. Aortic atherosclerosis, hypercoagulability, and stroke the APRIS (Aortic Plaque and Risk of Ischemic Stroke) study. J Am Coll Cardiol 2008;52: 855-861.

113. Bang OY, Seok JM, Kim SG, Hong JM, Kim HY, Lee J, et al. Ischemic stroke and cancer: stroke severely impacts cancer patients, while cancer increases the number of strokes. J Clin Neurol 2011;7:53-59.

114. Seok JM, Kim SG, Kim JW, Chung CS, Kim GM, Lee KH, et al. Coagulopathy and embolic signal in cancer patients with ischemic stroke. Ann Neurol 2010;68:213-219.

115. Kim SG, Hong JM, Kim HY, Lee J, Chung PW, Park KY, et al. Ischemic stroke in cancer patients with and without conventional mechanisms: a multicenter study in Korea. Stroke 2010; 41:798-801.

116. Kim SJ, Park JH, Lee MJ, Park YG, Ahn MJ, Bang OY. Clues to occult cancer in patients with ischemic stroke. PLoS One 2012;7:e44959.

117. Hron G, Kollars M, Weber H, Sagaster V, Quehenberger P, Eichinger $\mathrm{S}$, et al. Tissue factor-positive microparticles: cellular origin and association with coagulation activation in patients with colorectal cancer. Thromb Haemost 2007;97:119123.

118. Fernandez-Cadenas I, Del Rio-Espinola A, Carrera C, Domingues-Montanari S, Mendioroz M, Delgado P, et al. Role of the MMP9 gene in hemorrhagic transformations after tissue-type plasminogen activator treatment in stroke patients. Stroke 2012; 43:1398-1400.

119. Lackner P, Dietmann A, Beer R, Fischer M, Broessner G, Helbok R, et al. Cellular microparticles as a marker for cerebral vasospasm in spontaneous subarachnoid hemorrhage. Stroke 2010;41:2353-2357. 